\title{
Functional Characterization of Human Thyroid Tissue with Immunohistochemistry
}

\author{
Antongiulio Faggiano, ${ }^{1-3}$ Bernard Caillou, ${ }^{1}$ Ludovic Lacroix, ${ }^{2}$ Monique Talbot, ${ }^{1}$ Sebastiano Filetti, ${ }^{4}$ \\ Jean-Michel Bidart, ${ }^{2}$ and Martin Schlumberger ${ }^{3}$
}

Immunohistochemistry provides insights in the expression of functional proteins and of their localization in normal thyroid tissue and in thyroid diseases. In hyperfunctional thyroid tissues, staining for sodium/iodide symporter (NIS), pendrin, thyroid peroxidase (TPO), and thyroglobulin (Tg) is increased. In hypofunctioning thyroid tissues, NIS staining is markedly decreased; in benign hypofunctioning adenomas, the expression of the other functional proteins is unmodified or slightly decreased, whereas their expression is profoundly decreased or absent in differentiated thyroid carcinoma.

\section{Introduction}

$\mathbf{I}_{\text {teis }}^{\mathrm{r}}$

MMUNOHISTOCHEMISTRY STUDIES THE EXPRESSION OF PROteins and their localization at the cellular and subcellular level. The availability of a wide range of antibodies specifically directed against antigens and cells permits to better define the characteristics of tissues in health and diseases. Thyroid tissue offers an example for applications of immunohistochemistry: a large series of specific antigens are identified, specific antibodies are available, and various thyroid diseases are characterized.

This review describes advances afforded by immunohistochemistry for the functional characterization of follicular thyroid cells in health and diseases. In this attempt, the review focuses on the immunohistochemical evaluation of functional thyroid proteins, such as enzymes involved in iodide transport and organification and thyroid hormone production and secretion. Oncogenic proteins, including ret, ras, and braf, growth factors, and their receptors and signal transduction pathways, which are known to be involved in thyroid tumor development $(1,2)$, are not treated and discussed in this review.

Beyond functional characterization, immunohistochemistry may have other applications and may also afford diagnostic and prognostic information.

\section{Antibodies}

Generation of specific polyclonal and/or monoclonal antibodies against the protein of interest constitutes the basic step in the development of immunohistochemical methods. The protein can be purified from cell or tissue extracts or be produced from cloned cDNAs. In either case, large amounts of antigenic material are needed to immunize either rabbits or goats $(0.5-5 \mathrm{mg})$ for the production of polyclonal antibodies, or mice $(50-500 \mu \mathrm{g})$ for the generation of monoclonal antibodies. Polyclonal antisera often display high affinity for their corresponding antigen. However, limited quantities of antibodies can be obtained from a single animal, and their specificity may be low when contaminants are co-purified with the protein used for immunization. These limitations can be overcome with the use of monoclonal antibodies, but their production is more expensive and they usually display lower affinities. Some immunohistochemical studies of the thyroid gland are based on the use of monoclonal antibodies raised against highly purified proteins, such as Tg or TPO $(3,4)$.

Synthetic peptides representative of a given portion of the protein of interest can also be used to generate antibodies that bind specifically to the native molecule. In this case, short (15- to 20-mer) synthetic peptides are generally conjugated with large carrier proteins, such as albumin or hemocyanin, to elicit a stronger immune response. This approach is particularly useful when the protein itself is not easily available. It is difficult, for example, to purify sufficient quantities of transmembrane proteins without altering their native conformation. The primary structure of the putative protein must be deduced from genome sequencing. Specific polyclonal or monoclonal antibodies can be raised against the peptide and used to identify the gene product in tissue specimens. This

Departments of ${ }^{1}$ Pathology, ${ }^{2}$ Clinical Biology, and ${ }^{3}$ Nuclear Medicine and Endocrine Oncology, Commissariat à l'Energie Atomique LRC29V, Institut Gustave Roussy and University Paris Sud, Villejuif Cedex, France.

${ }^{4}$ Internal Medicine Department, University "La Sapienza," Rome, Italy.

Antongiulio Faggiano was a doctoral student in the frame of Italian-French collaborative education program and of the Diplome Universitaire de Cancérologie Clinique, University Paris Sud. 
approach has been successfully used for the study of transmembrane glycoproteins that play critical functional roles in the iodine metabolism of the thyrocyte, including the thyrotropin (thyroid-stimulating hormone) receptor (TSH-R), NIS, the pendrin, the apical iodine transporter (AIT), and flavoproteins involved in the production of hydrogen peroxide (dual oxidase [Duox]) (5-10). One major drawback for the use of anti-peptide antibodies is their lower affinity for native molecules compared to that of antibodies raised against the native protein itself. Indeed, these antibodies that preferentially bind to the denatured molecules are helpful for western immunoblotting experiments and for immunohistochemistry.

Genetic immunization is a promising method for generating antibodies against putative proteins whose structures have been deduced from the genome sequencing. An immune response is elicited by injecting a eukaryotic expression vector containing cDNA encoding the protein of interest, together with a strong promoter. Intramuscular injection is followed by a predominantly cellular response, while intradermal immunization favors the humoral response. Both polyclonal and monoclonal antibodies have been raised with this technique against the native structure of NIS and TSH-R $(11,12)$. This technique is currently considered more reliable than immunization with natural or recombinant protein for generating antibodies directed against conformationally determined epitopes.

\section{Methods}

For stabilizing cells in tissues and preventing alteration of proteins by proteases, many fixative solutions can be used. For a given antigen, preservation and revelation may strongly depend on the fixation procedure used, and best results can be obtained with one fixative and can be negative with another one. Thus, for any new polyclonal or monoclonal antibody, a large range of dilutions should be tested with different fixatives. Formalin remains the best compromise under most circumstances. However, for some antibodies, better results were obtained with Alcohol-Formol-Acetic-acid (AFA) or Bouin's fixative. The paraffin-embedded section, ranging $4-5 \mu \mathrm{m}$ thick, is initially deparaffinized by serial passages in xylene and in alcohol. Endogenous peroxidase activity is then quenched by incubation in $0.03 \%$ hydrogen peroxide and $0.1 \mathrm{M}$ Tris- $\mathrm{HCl}$ $1 \times$ buffer ( $\mathrm{pH} 7.6)$ for 5 minutes, and the tissue is placed in $1 \mathrm{mM}$ ethylenediaminetetraacetic acid (EDTA) buffer ( $\mathrm{pH} \mathrm{8)}$ and subjected to microwave/pressure cooker pretreatment (three cycles of 5 minutes each). Alternatively, citrate is another valid and commonly used buffer ( $\mathrm{pH}$ 6). Frozen sections are simply fixed in acetone for 10 minutes.

Sections are then incubated for 30-60 minutes at room temperature with the primary monoclonal or polyclonal antibody. Following three 5-minute washes in the Tris- $\mathrm{HCl} 1 \times$ buffer, they are incubated for 15 minutes with enzyme conjugated antibodies directed against the primary antibody. Several detection systems are available for immunohistochemistry, and those with peroxidase- or phosphatase-alkalineconjugated antibodies are the most frequently employed. After three additional washes, binding is revealed with diaminobenzidine tetrahydrochloride with $0.1 \%$ hydrogen peroxide in Tris buffer $0.01 \mathrm{M}$ ( $\mathrm{pH} 7.2$ ) (peroxidase-conjugated antibody) or BCIP/NTB (phosphatase-conjugated antibody). Sections are counterstained with hematoxylin, dehydrated, mounted, and examined under a microscope.

\section{Double immunostaining}

Double-immunostaining experiments are performed to investigate the localization of various antigens on the same tissue sample. An example of double-staining experiments reported is the study of NIS and pendrin localizations. This procedure includes sequential steps: (a) slides are immunostained with the anti-NIS rabbit antibody, as previously described (a peroxidase-conjugated anti-rabbit antibody is used as detection system); (b) after three washes, they are incubated with the anti-pendrin mouse antiserum for 30 minutes; (c) after three additional washes, sections are incubated with a phosphatase-alkaline-conjugated anti-mouse monoclonal antibody; (d) after three washes, phosphatase-alkaline staining is revealed with BCIP/NTB; (e) slides are counterstained with hematoxylin and mounted. In tissue, NIS immunostaining appears brown and pendrin immunostaining, blue. Two types of controls are performed on the same tissue samples and at the same time as double immunostaining: (a) single immunostaining with each antiserum, and (b) single immunostaining with the preimmune antisera.

\section{Controls and validation of results}

One limitation of immunohistochemistry is that negative results may not reliably indicate the absence of the target protein. For this reason, sensitivity should always be verified by including external and internal positive controls. The specificity of the antigen-antibody binding should also be verified with negative controls. Nonspecific reactions can be excluded by using an irrelevant primary antibody, by incubating sections with a preimmune antiserum, and by preabsorbing the primary antiserum with an excess of the corresponding peptide. Cells transfected in vitro with the gene of interest can also be used to provide both negative and positive controls.

\section{Semiquantitative analysis of protein expression}

Immunohistochemical techniques can demonstrate protein expression and its localization within tissues or cells. Quantification of the expression is more complicated, but staining intensity and number of positive cells should be evaluated on an adequate number of microscopic fields, and results are commonly expressed in terms of semiquantitative scores for each parameter.

\section{Relationships with Other Methods}

Immunohistochemistry is one of many techniques available for the study of protein expression that can be combined to improve the reliability of results. Real-time kinetic quantitative PCR (RT-PCR), for example, is a highly sensitive technique for quantifying gene expression in terms of mRNA product. RT-PCR and immunohistochemistry, when used together, provide an accurate characterization of gene expression at both mRNA and protein levels, and this may also permit the study of posttranscriptional mechanisms.

Immunohistochemistry is extremely valuable for localizing antigens of interest: it may identify thyroid follicles, intrafollicular areas, and/or cell types expressing a given protein. At the subcellular level, it may localize its expression within the nucleus, cytoplasm, or membrane. Membrane localization is particularly important in polarized cells, such as thyrocytes, since basal, lateral, and apical membranes display the ex- 
pression of different proteins with specific functions that are directly related to their location. Finally, direct relationships can be found between staining patterns and biochemical abnormalities associated with thyroid diseases (see below).

\section{Thyroid-Specific Genes}

\section{Biochemical pathways in thyrocytes}

Thyroid organization. Functional thyroid tissue is composed of follicles that are spheric structures containing the colloid and lined by a monolayer of thyroid epithelial cells, the thyrocytes. Functional studies with autoradiography and ion mass spectrometry have shown a large heterogeneity between follicles (13-15): small follicles lined by tall and cuboidal cells are considered active, and large follicles lined by flattened cells are considered less active.

lodine pathway. Thyrocytes are polarized cells, with a basal membrane in contact with vessels and an apical membrane in contact with the follicular lumen that contains the colloid. Iodide is first concentrated from the blood across the basolateral cell membrane of the thyrocyte. It then moves toward the apical pole and crosses the apical membrane to reach the follicular lumen. Organification of iodide in Tg molecules occurs at the external side of the apical membrane. The iodinated $\mathrm{Tg}(\mathrm{Tg}-\mathrm{I})$ is then stored in the follicular lumen. In normal follicles, Tg-I is integrated in the thyrocyte by an endocytic process. Tg-I undergoes proteolytic cleavage inside the thyrocyte to produce both thyroid hormones that are secreted into the bloodstream and iodotyrosines that are deiodinated by a deshalogenase (16).

Iodide transport involves several proteins. At the basolateral membrane, the sodium/iodide symporter (NIS, SLC5A5) actively co-transports $\mathrm{Na}^{+}$and $\mathrm{I}^{-}$from the blood into the thyrocyte $(7,17,18)$. At the apical membrane, other transporters may facilitate the efflux of iodide into the follicular lumen, but the role of two apical proteins, namely the pendrin (PDS gene, SLC26A4) and the apical iodine transporter (AIT, SLC5A8), is still not known $(8,9,19,20)$. Incorporation of iodide into tyrosyl residues of the $\mathrm{Tg}$ molecule and coupling of iodotyrosyl residues are both catalyzed by thyroid peroxidase (TPO) in the presence of hydrogen peroxide $\left(\mathrm{H}_{2} \mathrm{O}_{2}\right)(21,22)$. The $\mathrm{H}_{2} \mathrm{O}_{2}$ generation is catalyzed by Duox, an Nicotinamide Adenine Dinucleotide Phosphate (NADPH) membrane-bound thyroid oxidase $(10,23)$.

Polyclonal and monoclonal antibodies have been raised against each of these proteins (Table 1), and immunohisto- chemistry allowed the study of their expression in normal and tumor thyroid tissues.

Regulation pathway. The primary regulator of thyroid cell function is TSH. TSH binding to its membrane receptor on thyroid cells activates the cAMP cascade, with consequent upregulation of thyroid transcription factor-1 (TTF1), thyroid transcription factor-2 (TTF2), and human paired-box-protein (PAX8). These transcription factors enhance the expression of NIS, TPO, Tg, and TSH-R genes by binding to their specific promoters (24-28).

\section{Immunohistochemical characterization of thyroid tissues}

Normal thyroid tissue. NIS staining is restricted to the basolateral membrane (7), whereas staining for pendrin and AIT is limited to the apical membrane $(8,29$; Fig. 1A-C). Staining for NIS, pendrin, and AIT is heterogeneous. Some follicles are negative, and within positive follicles, only a minority of cells are stained: less than $25 \%$ of normal thyrocytes display staining for NIS, $30 \%$ to $50 \%$ for pendrin, and $10 \%$ to $40 \%$ for AIT. NIS staining is observed in some tall thyrocytes that are considered active. A small number of NIS-positive cells are contiguous and define a particular functioning area of the follicle that is close to blood vessels (Fig. 1A, superposed cut). In contrast, NIS staining is not detected in flattened thyrocytes that are considered inactive $(7,29)$. A similar picture is observed for pendrin, but follicular cells are more frequently positive for pendrin than for NIS.

TPO staining is homogeneous in the cytoplasm of the majority of thyroid cells, and is more intense at the apical membrane (4,30,31; Fig. 1D). Staining tends to be more intense in small follicles composed of tall thyrocytes than in larger ones surrounded by flattened cells (30). Duox expression is found in the majority of tall follicular cells, and is located at the apical membrane, whereas most flattened cells are negative (10,31; Fig. 1E).

$\mathrm{Tg}$ and $\mathrm{Tg}$-I staining is intense in the lumen of all follicles. Follicular cells can be $\mathrm{Tg}$ negative/ $\mathrm{Tg}$-I negative, $\mathrm{Tg}$ positive/ Tg-I negative, or Tg positive/Tg-I positive, probably reflecting their functional status, being resting, Tg-synthetizing, or hormone-producing cells, respectively (31; Fig. 1F, G).

TSH-R staining is present in all thyrocytes, and is restricted to the basal membrane and to a lesser extent to the lateral membrane (5,31; Fig. $1 \mathrm{H})$.

Table 1. Antibodies Directed Against Thyroid Antigens Used at IGR

\begin{tabular}{lccc}
\hline Antigen & Antibody & Dilution & Source \\
\hline NIS SLC5A5 & Polyclonal 1859 & $1 / 500$ & J.M. Bidart (IGR) \\
Pendrin SLC26A4 & Monoclonal (PDS 02) & $1 / 25$ & J.M. Bidart (IGR) \\
AIT SLC5A8 & Monoclonal (AIT 01) & J.M. Bidart (IGR) \\
TPO & Monoclonal (TPO 47) & Biocytex \\
Duox & Polyclonal 2776 & $1 / 500$ & A. Virion (IGR) \\
Thyroglobulin & Monoclonal (TG tg6) & $1 / 250$ & DAKO \\
Thyroxine & Polyclonal & $1 / 100$ & Biogenesis \\
TSH-R & Monoclonal (TSH-R 365) & $1 / 100$ & E. Milgrom (Paris Sud) \\
TTF1 & Monoclonal (TTF1 8G7G3/1) & DAKO \\
\hline
\end{tabular}

IGR: Institut Gustave Roussy; NIS: sodium/iodide symporter; AIT: apical iodine transporter; TPO: thyroid peroxidase; Duox: dual oxidase; TSH-R: thyroid-stimulating hormone receptor; TTF1: thyroid transcription factor-1. 

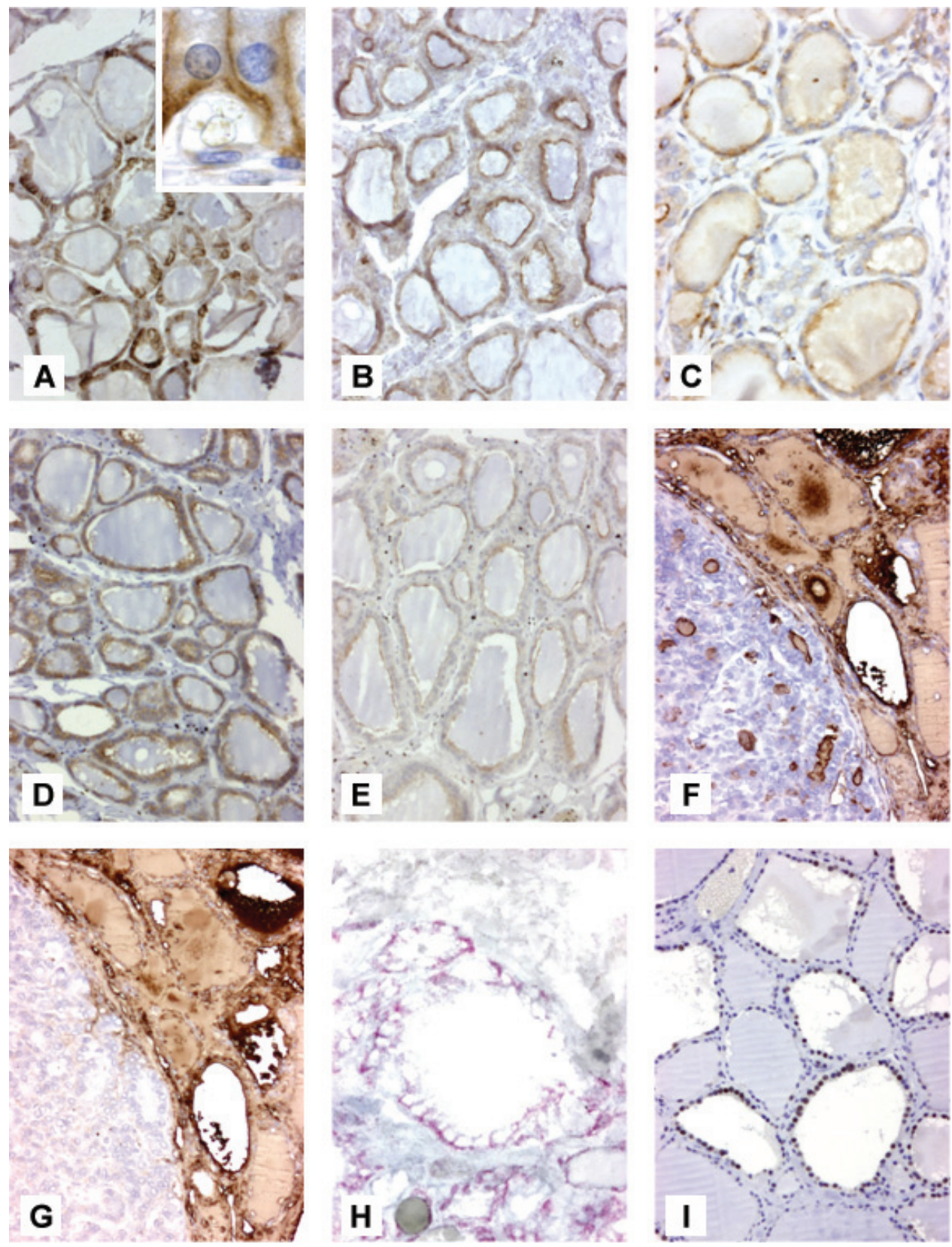

FIG. 1. Immunohistochemical expression of the biochemical pathway of thyrocytes in normal thyroid tissue (magnification, $\times 200$ ): (A) Sodium/iodide symporter (NIS) staining at the basolateral membrane; (B) pendrin staining at the apical membrane; (C) apical iodine transporter staining at the apical membrane; (D) thyroid peroxidase cytoplasmic staining associated to an apical membrane reinforcement; $(\mathbf{E})$ dual oxidase staining at the apical membrane; $(\mathbf{F})$ thyroglobulin $(\mathrm{Tg})$ staining in the lumen of follicles and in most follicular cells; (G) iodinated Tg staining in the lumen of follicles and in most follicular cells; (H) thyroid-stimulating hormone receptor staining at the basolateral membrane; (I) thyroid transcription factor-1 staining in most nuclei; (superposed cut in A) NIS-positive thyrocytes contiguous to blood vessels (magnification, $\times 1000$ ).

Staining for NIS, pendrin, AIT, TPO, Duox, Tg, Tg-I, and TSH-R is restricted to thyrocytes: antibodies do not react with lymphocytes, macrophages, vascular endothelial cells, or any stromal cell.

The percentage of thyrocytes stained for NIS, pendrin, and Duox is higher in thyroid tissues obtained in children less than 12 years of age. This is in agreement with the higher percentage of small follicles with tall or cuboidal cells observed during childhood. Staining for AIT and TPO does not vary with age (32).
Among thyroid transcription factors, TTF1 is the most well characterized. The majority of nuclei of normal thyroid tissue are strongly stained (Fig. 1I) (33).

Diffuse thyroid hyperplasia. The thyroid gland is increased in size and may contain nodules. Staining is highly variable. NIS and pendrin staining is usually restricted to defined areas inside a follicle constituted by tall thyrocytes that are close to vessels $(7,8)$. TSH-R and TPO staining is positive in virtually all thyrocytes (31). Tg staining is similar to 
that observed in normal thyroid tissue. Staining for Duox varies widely between follicles, but the average number of positive cells is similar to that of normal tissues (10). NIS, pendrin, and Duox staining is detected in the majority of thyrocytes of small follicles.

Graves' disease and toxic adenoma. NIS and pendrin staining is present in most follicular cells, with a stronger intensity than in normal tissue samples (Table 2; Fig. 2A, B) $(7,8)$ whereas AIT expression is similar or slightly decreased as compared to normal thyroid tissue (29). Staining for NIS is present not only on latero-basal membrane but also, with a weaker intensity, in the cytoplasm (Fig. 2C). Double-staining experiments indicate that NIS-positive/pendrin-positive thyrocytes (arrows) alternate with NIS-negative/pendrin-positive thyrocytes (34; Fig. 2D). TPO staining is stronger in all thyrocytes than in normal thyroid tissue $(30,31)$. Tg, Tg-I, and TSH-R stainings are generally stronger than in normal thyroid tissue $(5,31)$, whereas Duox staining is found only in few cells and with a much weaker intensity than in normal tissue (10).

Autoimmune thyroiditis. Staining for NIS and pendrin is found in a percentage of cells similar to normal thyroid tissue, but the distribution of positive cells is peculiar: thyrocytes in contact with lymphocytes are strongly stained, while the others are either negative or only weakly positive (7). In contrast, TPO, Tg, TSH-R, and Duox staining is similar to that observed in normal thyroid tissue in all thyrocytes, either in contact or not in contact with lymphocytic infiltrates.

Hypofunctioning follicular adenoma. NIS staining is totally negative in about $2 / 3$ of hypofunctioning adenomas; in the remaining third, fewer than $20 \%$ of the cells are stained (7) (Table 2). Pendrin expression is similar to normal tissues in 3/4 of cases, and is weak or even absent in the remaining samples that are also NIS-negative (8). AIT is expressed in a lower number of follicles and thyrocytes than in normal thyroid tissue, but stronger staining, similar to that found in normal thyroid tissue, is found in microfollicular adenomas and Hürthle cell tumors (29). TPO is generally expressed, but rare benign tumors are negative or weakly stained $(30,31)$. Staining for Tg and TSH-R is similar to normal thyroid tissue
$(5,31)$. Duox staining varies widely between adenomas and is related to follicle size, ranging from weak staining in a minority of cells in macrofollicular areas to diffuse and intense staining in microfollicular areas (10).

Papillary and follicular thyroid carcinomas. NIS and pendrin staining is totally negative in about $80 \%$ of differentiated thyroid cancers $(7,8)$. In positive samples, only rare cancer cells are NIS-positive, and a somewhat higher number of cells are pendrin-positive (Table 2; Fig. 3A, B). Interestingly, in papillary thyroid carcinomas that express these proteins, NIS staining is found in the basolateral membrane that is in contact with the vascular core of the papillae, while pendrin is found at the opposite pole, confirming the polarization of these tumor cells. In some studies, an unexpected increased NIS expression was reported in up to $2 / 3$ of the papillary thyroid carcinomas, with staining found in the intracellular compartments and in some cases also in the plasma membrane $(31,35)$. In some studies, cytoplasmic NIS staining was considered artifactual since it was found in paraffinembedded sections but not on cryostat-frozen sections (7). In addition, the mature NIS protein was not detected by immunoblot experiments in hypofunctioning thyroid tumors, and small amounts of nonglycosylated NIS proteins that were localized in the intracellular compartments were found in NIS transcript positive tumors (36-40). This shows abnormalities in NIS posttranscriptional maturation and targeting to the plasma membrane and may explain NIS positivity at immunohistochemistry. Similarly, pendrin staining was found in more than $70 \%$ of differentiated thyroid carcinomas at the cytoplasmic level only (41). AIT staining is negative in most differentiated thyroid carcinomas (Fig. 3C).

Positive polyclonal antibody staining for TPO is observed in more than $50 \%$ of papillary carcinomas. However, staining with the monoclonal antibody MoAb47 is weak or absent in the large majority of papillary and follicular thyroid carcinomas, reflecting both a decreased expression and structural abnormalities in the TPO molecule (4,30; Fig. 3D).

Duox staining is found in almost $80 \%$ of papillary and follicular thyroid carcinomas (42). Staining is found in both the cytoplasm and the apical membrane of cancer cells (Fig. $3 \mathrm{E}, \mathrm{F})$. Among positive tumors, the percentage of stained

Table 2. Expression Level of Functional Thyroid Proteins as Shown by Immunohistochemistry in Graves' Disease, Hypofunctioning Follicular Adenoma, and Differentiated Thyroid Carcinoma, as Compared to Normal Thyroid Tissue

\begin{tabular}{llll}
\hline Antigen & \multicolumn{1}{c}{ Graves' disease } & \multicolumn{1}{c}{$\begin{array}{c}\text { Hypofunctioning } \\
\text { follicular adenoma }\end{array}$} & $\begin{array}{c}\text { Differentiated thyroid } \\
\text { carcinoma }\end{array}$ \\
\hline NIS (SLC5A5) & Increased & Decreased & Decreased or absent \\
Pendrin (SLC26A4) & Increased & Unmodified or decreased & Decreased or absent \\
AIT (SLC5A8) & Unmodified or decreased & Unmodified or decreased & Decreased or absent \\
TPO & Increased & Unmodified or decreased & Decreased or absent \\
Duox & Decreased & Unmodified or decreased & Decreased, only rarely absent \\
Tg & Increased & Unmodified or decreased & Decreased \\
Tg-I & Increased & Unmodified & Absent \\
TSH-R & Increased & Unmodified & Decreased \\
TTF1 & Unmodified & Unmodified & Increased \\
\hline
\end{tabular}

${ }^{\mathrm{a}}$ In microfollicular and Hurthle cell adenoma.

NIS: sodium/iodide symporter; AIT: apical iodine transporter; TPO: thyroid peroxidase; Duox: dual oxidase; Tg: thyroglobulin; Tg-I: iodinated Tg; TSH-R: thyroid-stimulating hormone receptor; TTF1: thyroid transcription factor-1. 

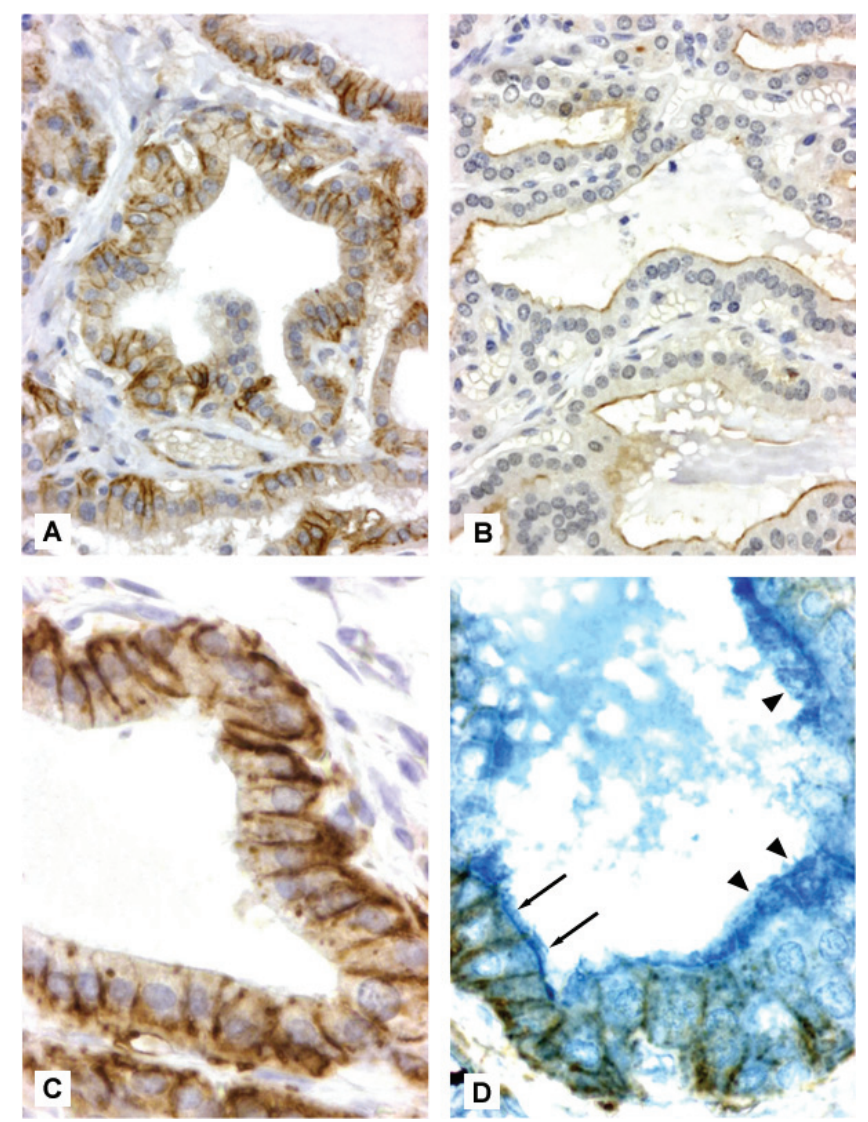

FIG. 2. Immunohistochemical expression of sodium/iodide symporter (NIS) and pendrin in Graves' disease. (A) NIS and (B) pendrin stainings are stronger than in normal thyroid tissue (magnification, $\times 200$ ). (C) NIS localization at the basolateral membrane and in the cytoplasm of thyrocytes (magnification, $\times 400$ ). (D) Double-stained thyrocytes with NIS in brown and pendrin in blue: NIS-positive/pendrin-positive thyrocytes (arrows) alternate with NIS-negative/pendrin-positive thyrocytes (arrowheads) (magnification, $\times 400$ ).

follicular cells is highly variable. Among patients with distant metastases, Duox staining is positive in all tumors with ${ }^{131} \mathrm{I}$ uptake and in only half of tumors with no demonstrable ${ }^{131} \mathrm{I}$ uptake. Among Duox positive thyroid tumors, fewer than $10 \%$ are stained for NIS, $40 \%$ for pendrin, and $50 \%$ for TPO. In contrast, all Duox negative thyroid tumors are also negative for NIS and pendrin, and only $20 \%$ are positive for TPO.

$\mathrm{Tg}$ staining is detected in all differentiated thyroid carcinomas, but its intensity is lower than in normal thyroid tissue (43). Tg-I staining is absent in all thyroid cancer tissues (31), depicting a characteristic Tg-positive/Tg-I-negative picture (Fig. 3G, H).

TSH-R staining in well-differentiated and minimally invasive follicular carcinomas is more heterogeneous and weaker than in hypofunctioning adenomas and in normal thyroid tissue (44), and is present only at the cytoplasmic level (5). In papillary carcinomas, TSH-R staining varies widely from one area to another, and within positive areas, cells are either positive or negative. When present, staining is restricted to the basolateral membrane in contact with the vascular core of the papillae, confirming the polarization of these cells (31).
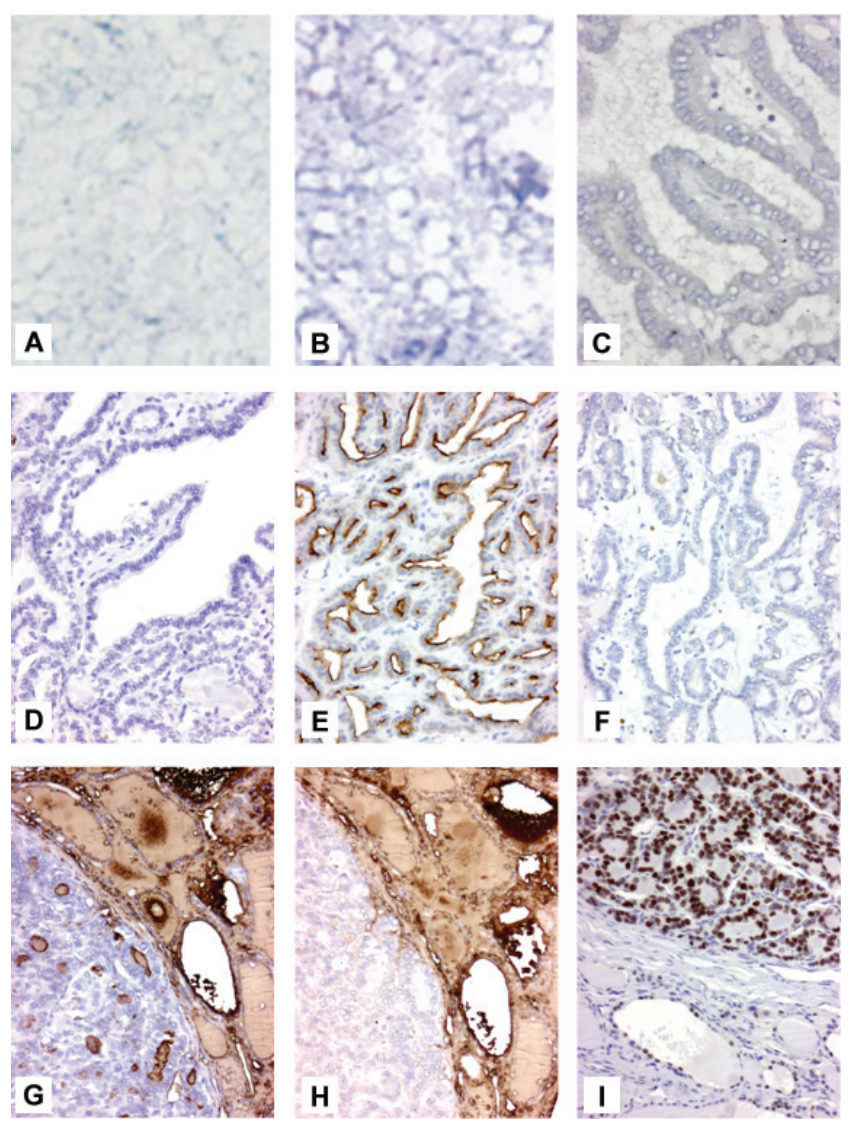

FIG. 3. Immunohistochemical studies in differentiated thyroid cancer. (A) Sodium/iodide symporter negative staining in all tumor cells in a papillary thyroid carcinoma (magnification, $\times 200)$; (B) pendrin positive staining in a minority of tumor cells in a papillary thyroid carcinoma (magnification, $\times 200)$; (C) apical iodine transporter negative staining in all tumor cells in a papillary thyroid carcinoma (magnification, $\times 200)$; (D) thyroid peroxidase negative staining in all tumor cells in a papillary thyroid carcinoma (magnification, $\times 100$ ); (E) dual oxidase (Duox) positive staining at the apical membrane and in the cytoplasm in a papillary thyroid carcinoma (magnification, $\times 100$ ); (F) Duox negative staining in all tumor cells in a papillary thyroid carcinoma (magnification, $\times 100)$; $(\mathbf{G})$ thyroglobulin $(\mathrm{Tg})$ positive staining in only few follicles and thyrocytes in a follicular thyroid carcinoma, and highly positive Tg staining in normal thyroid tissue (magnification, $\times 100$ ); $(\mathbf{H})$ iodinated Tg negative staining in a follicular thyroid carcinoma and positive staining in normal thyroid tissue (magnification, $\times 100$ ); (I) thyroid transcription factor-1 positive staining in all tumor cell nuclei in a follicular thyroid carcinoma (magnification, $\times 100$ ).

TTF1 is strongly expressed in differentiated thyroid tumors (33,45; Fig. 3I). In papillary thyroid carcinoma, TTF1 staining is increased in aggressive tumors $(46,47)$.

In poorly differentiated and widely invasive follicular thyroid carcinomas, no staining is observed for NIS, pendrin, AIT, and TPO. Tg staining is observed in only a minority of cells, and TSH-R staining is weaker and more heterogeneous than in well-differentiated tumors. Duox staining is found at the apical membrane and in the cytoplasm in a minority of cases. A low TTF1 staining is found in $25 \%$ to $42 \%$ of cases $(33,45)$. 
In anaplastic carcinomas, there is no detectable staining for NIS, pendrin, TPO, Tg, and TSH-R (48), and only focal staining for TTF1 (45). Tg staining, when present, is related to a diffusion of $\mathrm{Tg}$ from a differentiated component or to entrapped differentiated follicular cells.

\section{Implications of immunohistochemistry}

Pathophysiology. The localization of thyroid-specific proteins (basolateral for NIS and TSH-R, and apical for pendrin, AIT, TPO, and Duox) is closely related to their functional roles. Various expression patterns are observed among follicles in normal thyroid tissues and are in close accordance with their iodine concentrating ability, as shown by autoradiography and ion microscopy (13-15). Staining for NIS, pendrin, and Duox thus differentiates between active follicles, small follicles composed of tall/cuboidal thyrocytes, which are characterized by a strong expression of these proteins, and follicles with a depressed functional activity, which are larger in size and with flattened thyrocytes and that express these proteins either weakly or not at all (32). In contrast, TPO, Tg, and TSH-R expression is not related with the morphological features of the thyrocytes or follicles.

Abnormal expression of thyroid-specific proteins is closely related to various defects of iodine metabolism that characterize neoplastic follicular cells, for example, decreased iodide concentration, decreased iodide organification, and low rate of $\mathrm{Tg}$ iodination and of hormone synthesis (36-39). When no iodide uptake is found in the metastases, staining for NIS and pendrin is absent, and when iodide uptake is found, NIS staining is highly variable between studies, and these discrepancies may be related to the antibody used. One study using an NIS monoclonal antibody in recurrent differentiated thyroid cancer highlighted a positive predictive value of $79 \%$ of NIS staining on ${ }^{131}$ I uptake and a negative predictive value of $62 \%$, while another study using a polyclonal antibody highlighted a positive predictive value of $100 \%$ and a negative predictive value of $46 \%(35,49)$.

TSH-R staining is detected in most thyroid carcinomas, and this is consistent with in vivo findings that demonstrate that all papillary and follicular thyroid carcinomas are TSH sensitive, and confirms the need of treating all these patients with thyroxine $(7,31,44)$.

Immunohistochemical findings at the protein level and results of quantitative RT-PCR or northern blots at the RNA messenger level indicate that alterations of iodine metabolism in thyroid tumors are related to alterations in gene expression, and that abnormalities in posttraductional maturation and targeting to the plasma cell membrane may also exist. NIS expression is increased in hyperfunctioning thyroid tissues and decreased in both benign and malignant hypofunctioning thyroid tumors. TPO expression is decreased in malignant tumors and is normal in benign tumors, while Duox expression is increased in some hypofunctioning thyroid tumors, either benign or malignant. These observations clearly show that the mechanisms regulating Duox expression are different from those controlling the expression of other thyroidspecific proteins. In anaplastic thyroid carcinomas, none of the thyroid-specific proteins are significantly expressed.

Diagnosis of thyroid cancer. Tg is expressed in all differentiated tumors of follicular origin, both benign and ma- lignant, and is the most useful marker for confirming the follicular origin of any thyroid tumor, with a specificity and a sensitivity close to $100 \%$ (44). Tg immunostaining is particularly useful for confirming the thyroid follicular origin of atypical tumors (primary thyroid tumors or undiagnosed tumors of the neck) and of distant metastases (50).

Immunohistochemistry has also proved to be useful for the diagnosis of benign and malignant follicular tumors. Indeed, in malignant thyroid tumors, an abnormal TPO structure results in a lower affinity for the monoclonal antibody MoAb47, and negative TPO staining is considered a marker of malignancy in follicular cell-derived tumors, both on cytological and histological specimens $(4,30)$.

In normal and hyperplastic tissues, the distribution of TTF-1 correlates to that of thyroid-specific proteins, while a heterogeneous distribution occurs in thyroid tumors $(33,47)$. In differentiated thyroid cancers, the nuclear TTF-1 staining seems to predict tumor recurrence (46). Anaplastic thyroid carcinoma is negative for all thyroid-specific proteins, including TTF1, and positive for cytokeratins. Therefore, immunostaining is used in this case to exclude the diagnosis. Negative staining for calcitonin and carcinoembryonic antigen permits the exclusion of a medullary thyroid carcinoma, and negative staining for the common leukocyte antigen (CLA) permits the exclusion of a malignant lymphoma (51).

Biomarker conservation in primary and in metastatic thyroid tumors. In a limited number of studies, there is no significant difference in the expression of thyroid-specific proteins between the primary thyroid tumor and in the corresponding lymph node metastases. Similarly, when distant metastases are present, they are consistently positive for $\mathrm{Tg}$ expression (31).

\section{Acknowledgments}

This study was partially supported by the "Fondazione Umberto Di Mario ONLUS."

\section{References}

1. Fagin JA 1994 Molecular genetics of human thyroid neoplasms. Annu Rev Med 45:45-52.

2. Santoro M, Melillo RM, Fusco A 2006 RET/PTC activation in papillary thyroid carcinoma: European Journal of Endocrinology Prize Lecture. Eur J Endocrinol 155:645-653.

3. Bellet D, Schlumberger M, Bidart JM, Assicot M, Caillou B, Motte P, Vignal A, Bohuon C 1983 Production and in vitro utilization of monoclonal antibodies to human thyroglobulin. J Clin Endocrinol Metab 56:530-533.

4. De Micco C, Kopp F, Vassko V, Grino M 2000 In situ hybridization and immunohistochemistry study of thyroid peroxidase expression in thyroid tumors. Thyroid 10:109-115.

5. Mizukami Y, Hashimoto T, Nonomura A, Michigishi T, Nakamura S, Noguchi M, Matsukawa S 1994 Immunohistochemical demonstration of thyrotropin (TSH)-receptor in normal and diseased human thyroid tissues using monoclonal antibody against recombinant human TSH-receptor protein. J Clin Endocrinol Metab 79:616-619.

6. Castro MR, Berger ER, Beito TG, McIver B, Goellner JR, Morris JC 1999 Development of monoclonal antibodies against the human sodium iodide symporter: immunohistochemical characterization of this protein in thyroids cells. J Clin Endocrinol Metab 84:2957-2962. 
7. Caillou B, Troalen F, Baudin E, Talbot M, Filetti S, Schlumberger M, Bidart JM $1998 \mathrm{Na}^{+} / \mathrm{I}^{-}$symporter distribution in human thyroid tissues: an immunohistochemical study. J Clin Endocrinol Metab 83:4102-4106.

8. Bidart JM, Mian C, Lazar V, Russo D, Filetti S, Caillou B, Schlumberger M 2000 Expression of Pendrin and the Pendred syndrome (PDS) gene in human thyroid tissues. J Clin Endocrinol Metab 85:2028-2033.

9. Rodriguez AM, Perron B, Lacroix L, Caillou B, Leblanc G, Schlumberger M, Bidart JM, Pourcher T 2002 Identification and characterization of a putative human iodide transporter located at the apical membrane of thyrocytes. J Clin Endocrinol Metab 87:3500-3503.

10. Caillou B, Dupuy C, Lacroix L, Nocera M, Talbot M, Ohayon R, Deme D, Bidart JM, Schlumberger M, Virion A 2001 Expression of reduced nicotinamide adenine dinucleotide phosphate oxidase (ThoX, LNOX, Duox) genes and proteins in human thyroid tissues. J Clin Endocrinol Metab 86:3351-3358.

11. Costagliola S, Rodien P, Many MC, Ludgate M, Vassart G 1998 Genetic immunization against the human thyrotropin receptor causes thyroiditis and allows production of monoclonal antibodies recognizing the native receptor. J Immunol 160:1458-1465.

12. Costagliola S, Many MC, Denef JF, Pohlenz J, Refetoff S, Vassart G 2000 Genetic immunization of outbred mice with thyrotropin receptor cDNA provides a model of Graves' disease. J Clin Invest 105:803-811.

13. Studer H, Forster R, Conti A, Kohler H, Haeberli A, Engler H 1978 Transformation of normal follicles into thyrotropin refractory "cold" follicles in the aging mouse thyroid gland. Endocrinology 102:1576-1586.

14. Mestdagh C, Many MC, Halpern S, Briancon C, Fragu P, Denef JF 1990 Correlated autoradiografic and ion-microscopic study of the role of iodine in the formation of "cold" follicles in young and old mice. Cell Tissue Res 260:449-457.

15. Schürch M, Peter HJ, Gerber H, Studer H 1990 Cold follicles in a multinodular goiter arise partly from a failing iodide pump and partly from deficient iodine organification. J Clin Endocrinol Metab 71:1224-1229.

16. Dunn AD 2000 Thyroglobulin: chemistry, biosynthesis, and proteolysis. In: Braverman LE, Utiger RD (eds) Werner and Ingbar's the Thyroid, 8th edition. Lippincott Williams \& Wilkins, Philadelphia, pp 91-104.

17. Dai G, Levy O, Carrasco N 1996 Cloning and characterization of the thyroid iodide transporter. Nature 379:458-460.

18. Smanik PA, Liu Q, Furminger TL, Ryu K-Y, Xing S, Mazzaferri EL, Jhiang SM 1996 Cloning of the human sodium iodide symporter. Biochem Biophys Res Commun 226:339-345.

19. Scott DA, Wang R, Kreman TM, Sheffield VC, Karnishki LP 1999 The Pendred syndrome gene encodes a chloride-iodide transport protein. Nat Genet 21:440-443.

20. Royaux IE, Suzuki K, Mori A, Katoh R, Everett L, Kohn LD, Green E 2000 Pendrin, the protein encoded by the Pendred syndrome (PDS) gene, is an apical porter in the thyroid and is regulated by thyroglobulin in FRTL-5 cells. Endocrinology 141:839-845.

21. Taurog A 2000 Hormone synthesis: thyroid iodine metabolism. In: Braverman LE, Utiger RD (eds) Werner and Ingbar's the Thyroid, 8th edition. Lippincott Williams \& Wilkins, Philadelphia, pp 61-85.

22. Corvilain B, Van Sande J, Laurent E, Dumont JE 1991 The $\mathrm{H}_{2} \mathrm{O}_{2}$-generating system modulates protein iodination and the activity of the pentose phosphate pathway in dog thyroid. Endocrinology 128:779-785.
23. Leseney AM, Dème D, Legue $O$, Ohayon R, Chanson $P$, Sales JP, Pires de Carvalho D, Dupuy C, Virion A 1999 Biochemical characterization of a Ca ${ }^{2+} / \mathrm{NAD}(\mathrm{P}) \mathrm{H}$-dependent $\mathrm{H}_{2} \mathrm{O}_{2-}$ generator in human thyroid tissue. Biochimie 81:373-380.

24. Trueba SS, Auge J, Mattei G, Etchevers H, Martinovic J, Czernichow P, Vekemans M, Polak M, Attie-Bitach T 2005 PAX8, TITF1, and FOXE1 gene expression patterns during human development: new insights into human thyroid development and thyroid dysgenesis-associated malformations. J Clin Endocrinol Metab 90:455-462.

25. Fabbro D, Di Loreto C, Beltrami CA, Belfiore A, Di Lauro R, Damante G 1994 Expression of thyroid-specific transcription factors TTF-1 and PAX-8 in human thyroid neoplasms. Cancer Res 54:4744-4749.

26. Ohmori M, Endo T, Harii N, Onaya T 1998 A novel thyroid transcription factor is essential for thyrotropin-induced upregulation of $\mathrm{Na}^{+} / \mathrm{I}^{-}$symporter gene expression. Mol Endocrinol 12:727-736.

27. Filetti S, Bidart JM, Arturi F, Caillou B, Russo D, Schlumberger M 1999 Sodium iodide symporter: a key transport system in thyroid cancer cell metabolism. Eur J Endocrinol 141:443-457.

28. Jhiang SM, Cho JY, Ryu KY, DeYoung BR, Smanik PA, McGaughy VR, Fisher AH, Mazzaferri EL 1998 An immunohistochemical study of $\mathrm{Na}^{+} / \mathrm{I}^{-}$symporter in human thyroid tissues and salivary gland tissues. Endocrinology 139:44164419.

29. Lacroix L, Pourcher T, Magnon C, Bellon N, Talbot M, Intaraphairot T, Caillou B, Schlumberger M, Bidart JM 2004 Expression of the apical iodide transporter in human thyroid tissues: a comparison study with other iodide transporters. J Clin Endocrinol Metab 89:1423-1428.

30. De Micco C, Ruf J, Chrestian MA, Gros N, Henry JF, Carayon P 1991 Immunohistochemical study of thyroid peroxidase in normal, hyperplastic, and neoplastic human thyroid tissues. Cancer 67:3036-3041.

31. Gerard AC, Daumerie C, Mestdagh C, Gohy S, De Burbure C, Costagliola S, Miot F, Nollevaux MC, Denef JF, Rahier J, Franc B, De Vijlder JJ, Colin IM, Many MC 2003 Correlation between the loss of thyroglobulin iodination and the expression of thyroid-specific proteins involved in iodine metabolism in thyroid carcinomas. J Clin Endocrinol Metab 88:4977-4983.

32. Faggiano A, Coulot J, Bellon N, Talbot M, Caillou B, Ricard M, Bidart JM, Schlumberger M 2004 Age-dependent variation of follicular size and expression of iodine transporters in human thyroid tissue. J Nucl Med 45:232-237.

33. Katoh R, Kawaoi A, Miyagi E, Li X, Suzuki K, Nakamura Y, Kakudo K 2000 Thyroid transcription factor-1 in normal, hyperplastic, and neoplastic follicular thyroid cells examined by immunohistochemistry and nonradioactive in situ hybridization. Mod Pathol 13:570-576.

34. Mian C, Lacroix L, Alzieu L, Nocera M, Talbot M, Bidart JM, Schlumberger M, Caillou B 2001 Sodium iodide symporter and pendrin expression in human thyroid tissues. Thyroid 11:825-830.

35. Castro MR, Bergert ER, Goellner JR, Hay ID, Morris JC 2001 Immunohistochemical analysis of sodium iodide symporter expression in metastatic differentiated thyroid cancer: correlation with radioiodine uptake. J Clin Endocrinol Metab 86:5627-5632.

36. Saito T, Endo T, Kawaguchi A, Ikeda M, Katoh R, Kawaol A, Muramatsu A, Onaya T 1998 Increased expression of the sodium/iodide symporter in papillary thyroid carcinomas. J Clin Invest 101:1296-1300. 
37. Dohan O, Baloch Z, Banrevi Z, Livolsi V, Carrasco N 2001 Predominant intracellular overexpression of the $\mathrm{Na}^{+} / \mathrm{I}^{-}$ symporter (NIS) in a large sampling of thyroid cancer cases. J Clin Endocrinol Metab 86:2697-2700.

38. Kaminski SM, Levy O, Salvador C, Dai G, Carrasco N 1994 $\mathrm{Na}^{+} / \mathrm{I}^{-}$symporter activity is present in membrane vesicles from thyrotropin-deprived non- $\mathrm{I}^{-}$-transporting cultured thyroid cells. Proc Natl Acad Sci USA 91:3789-3793.

39. Riedel C, Levy O, Carrasco N 2001 Post-transcriptional regulation of the sodium/iodide symporter (NIS) by thyrotropin. J Biol Chem 276:21458-21463.

40. Trouttet-Masson S, Selmi-Ruby S, Bernier-Valentin F, Porra V, Berger-Dutrieux N, Decaussin M, Peix JL, Perrin A, Bournaud C, Orgiazzi J, Borson-Chazot F, Franc B, Rousset B 2004 Evidence for transcriptional and posttranscriptional alterations of the sodium/iodide symporter expression in hypofunctioning benign and malignant thyroid tumors. Am J Pathol 165:25-34.

41. Skubis-Zegadlo J, Nikodemska A, Przytula E, Mikula M, Bardadin K, Ostrowski J, Wenzel BE, Czarnocka B 2005 Expression of pendrin in benign and malignant thyroid tissues. Br J Cancer 93:144-151.

42. Lacroix L, Nocera M, Mian C, Caillou B, Virion A, Dupuy C, Filetti S, Bidart JM, Schlumberger M 2001 Expression of nicotinamide adenine dinucleotide phosphate oxidase flavoprotein Duox genes and proteins in human papillary and follicular thyroid carcinomas. Thyroid 11:1017-1023.

43. Harach HR, Franssila KO 1988 Thyroglobulin immunostaining in follicular thyroid carcinoma: relationship to the degree of differentiation and cell type. Histopathology 13: 43-54.

44. Tanaka K, Inoue H, Miki H, Masuda E, Kitaichi M, Komaki K, Uyama T, Monden Y 1997 Relationship between prognostic score and thyrotropin receptor (TSH-R) in papillary thyroid carcinoma: immunohistochemical detection of TSH-R. Br J Cancer 76:594-599.

45. Choi YL, Kim MK, Suh JW, Han J, Kim JH, Yang JH, Nam SJ 2005 Immunoexpression of HBME-1, high molecular weight cytokeratin, cytokeratin 19, thyroid transcription factor-1, and E-cadherin in thyroid carcinomas. J Korean Med Sci 20:853-859.

46. Fenton CL, Patel A, Burch HB, Tuttle RM, Francis GL 2001 Nuclear localization of thyroid transcription factor-1 correlates with serum thyrotropin activity and may be increased in differentiated thyroid carcinomas with aggressive clinical course. Ann Clin Lab Sci 31:245-252.

47. Lacroix L, Michiels S, Mian C, Arturi F, Caillou B, Filetti S, Schlumberger M, Bidart JM 2006 HEX, PAX-8 and TTF-1 gene expression in human thyroid tissues: a comparative analysis with other genes involved in iodide metabolism. Clin Endocrinol 64:398-404.

48. Venkatesh YS, Ordonez NG, Schultz PN, Hickey RC, Goepfert H, Samaan NA 1990 Anaplastic carcinoma of the thyroid. A clinicopathologic study of 121 cases. Cancer 66: 321-330.

49. Min JJ, Chung JK, Lee YJ, Jeong JM, Lee DS, Jang JJ, Lee MC, Cho BY 2001 Relationship between expression of the sodium/iodide symporter and 131I uptake in recurrent lesions of differentiated thyroid carcinoma. Eur J Nucl Med 28:639-645.

50. Schlumberger M 1998 Papillary and follicular thyroid carcinoma. N Engl J Med 338:297-306.

51. Rosai J 2003 Immunohistochemical markers of thyroid tumors: significance and diagnostic applications. Tumori 89: 517-519.

Address reprint requests to: Martin Schlumberger, M.D. Department of Nuclear Medicine and Endocrine Oncology Institut Gustave-Roussy 39 rue C. Desmoulins 94805 Villejuif France

E-mail: schlumbg@igr.fr 
